Research Article

\title{
A New Model of Manufacturer's Optimal Product Supply Strategy in the Context of Precision Marketing: Based on Real Demand Pattern
}

\author{
Zhiyi Zhuo $\mathbb{D}^{1},{ }^{1}$ Shuhong Chen $\mathbb{D}^{2},{ }^{2}$ and Ka Yin Chau $\mathbb{D}^{3}$ \\ ${ }^{1}$ School of Business, Wuyi University, Wuyishan 354300, Fujian, China \\ ${ }^{2}$ School of Mathematics and Statistics, Minnan Normal University, Zhangzhou 363000, Fujian, China \\ ${ }^{3}$ Faculty of Business, City University of Macau, Macau, Macao, China \\ Correspondence should be addressed to Ka Yin Chau; gavinchau@cityu.mo
}

Received 8 May 2020; Revised 24 November 2020; Accepted 5 December 2020; Published 21 December 2020

Academic Editor: Francesc Pozo

Copyright (c) 2020 Zhiyi Zhuo et al. This is an open access article distributed under the Creative Commons Attribution License, which permits unrestricted use, distribution, and reproduction in any medium, provided the original work is properly cited.

Precision marketing has a crucial impact on whether a manufacturer can make the most profit. This paper conducts precision marketing based on customer demand and analyzes how developers should formulate the quantity and pricing of products to obtain optimal profit in the case of real demand of customers. First, the research status of the development of precision marketing and its demand for its theoretical influence is introduced. Secondly, an appropriate real demand function is constructed, according to the characteristics of the product and consumer positioning, combined with the expression of the demand function in economics. Thirdly, by using the constructed "real demand" function and combining the basic knowledge of optimization and probability theories, the profit function for manufacturers in "real demand" pattern is established. When the manufacturer wishes to obtain optimal profit from three different sales models, the product manufacturing quantity and pricing are analyzed. Finally, an example is given to verify the results of the previous analysis.

\section{Introduction}

Social progress and the development of science and technology have meant that goods can no longer be sold using the traditional concept of "good wine needs no bush," and today more publicity and the exploration of various forms of sales channels is needed. Advertising blindly will not only be a waste of human, material, and financial resources but also increase the cost of products. Therefore, only precision marketing can effectively expand product sales and reasonably limit product costs to achieve increased profits.

One important factor in the implementation of precision marketing is meeting customer needs. Marxist philosophy proposed that the price of commodities fluctuates around the value of given commodities; in fact, what affects the fluctuation of commodity prices is the relationship between customer demand and commodity supply. When the supply of commodities exceeds demand, the price becomes relatively low and even fluctuates below the value of commodities. When the supply of commodities is less than demand, the price is higher. Therefore, customer demand is closely related to manufacturer profit. In addition, from the perspective of supply and demand theory, demand refers to the state of feeling the necessity of things and the requirement to actually purchase a specific product or service. It refers to the human desire for a certain product or service and the willingness to pay a particular price for it [1]. From a consumer goods supply chain perspective, customer demand forms the core of product sales. To obtain maximum profit then, not only should manufacturers consider investing in modern production technology, open innovation platforms, communication technology, and other innovative factors, but they should also comprehensively consider the influencing factor of customer demand such 
as product preference, market demand information, and personalized customization. From a retail point of view, it is also necessary to expand the product diversity according to the characteristics of customer demand and customer preference, in addition to grouping and selling products according to customer buying habits. These factors indicate that the development of product production and sales is driven by customer demand. Customer preference for products greatly affects the degree of market segmentation and also determines the benefits to manufacturers and retailers. Therefore, how manufacturers and retailers design and plan different supply strategies, based on demand information, while maximizing product profits has become the focus for businesses. To reduce the cost of sales and increase product profits, manufacturers and retailers mainly consider the influence of controlling product cost and price, expanding sales volume and customer demand.

Manufacturers develop different policies and methods to control the price and reduce the cost of products in various ways. Wang et al. [2] used the Lagrange model to study the optimal pricing and product strategy for manufacturers and concluded that, according to the guest pricing (NYOP) mechanism, the optimal strategy of manufacturers mainly depends on the bidding cost, manufacturing cost savings, production capacity, and market size. Li and Lim [3] conducted a clustering analysis of data from the SKU store daily demand retailer database in Singapore and found that the real-world seasonal demand forecast could be achieved by establishing an effective inventory and logistics management system, thereby reducing the sales cost of products. Chanda and Kumar [4] found that demand follows the life cycle of a phenomenon; it has a dynamic limit to potential adopters and is sensitive to advertising spend and unit price. Therefore, an economic order quantity model has been developed to find strategies for companies selling technical products with a limited plan scope, and numerical examples can be used to verify the effectiveness of this model. Palanivel and Uthayakumar [5] proposed an Economic Production Quantity (EPQ) model for items where demand deteriorates in accordance with the business sales plan involving probabilistic deterioration. By finding the optimal cycle length and quantity, the model helps to reduce the manufacturer's total inventory cost. Numerical examples show that the total cost is minimized when deterioration is evenly distributed and when the sales team initiative is equal to 1 .

In terms of increasing sales channels, such as sales channels with uncertain demand, online sales, and increasing sales volume, Zhang et al. [6] studied the channel structure selection and pricing decisions of retailers in the supply chain between manufacturers and retailers. The optimal wholesale price of manufacturers and the optimal retail price of retailers are first obtained under all three possible channel structures of purely offline, purely online, and dual channels. Then, how changes in channel structure affect pricing decisions and retailers' optimal channel structure are investigated. Zhang et al. [7] studied the strategies of preorder-online, pickup-in-store (POPU) of dual-channel retailers. Researches found that POPU strategies can reduce retailers' market share and profits in monopolistic situations. When the operating cost of the POPU model is low, meanwhile, the POPU strategy can increase the retailers' market share and profits. He et al. [8] considered the dual-channel closed-loop supply chain (CLSC), and manufacturers can distribute new products through independent retailers with possible government subsidies and sell remanufactured products through third-party companies or platforms (3Ps). Three possible channel structures of manufacturers are studied in this research.

First are non-direct sales (Structure D). Second, new products are sold directly, but remanufactured products are distributed through $3 \mathrm{P}$ (structure $\mathrm{MN}$ ). Third is direct sale of remanufactured products, but the distribution of new products through retailers (Structure MR). The optimal channel structure and pricing decision of manufacturers and the optimal government subsidy level are obtained under these three channel structures. He and Zhao [9] considered that the supplier's supply chain is subject to revenue uncertainty, and it is sold to retailers facing random demand. It is found that the classical coordination contract cannot coordinate the supplier's production and the retailer's purchasing decision and cannot achieve efficient performance. It is also found that an Advance Purchase Discount (APD) with a revenuesharing contract can effectively coordinate the supply chain and enables flexible profit distribution. He and Zhao [10] studied the inventory, production, and contract decisions in multilevel supply chains with demand and supply uncertainties. Studies proposed return policies used by manufacturers and retailers and combined the wholesale price contracts used by raw material suppliers and manufacturers to perfectly coordinate the supply chain. Studies also investigated the impact of suppliers' risk attitude on decision-making and the impact of spot market price of raw materials on the performance of the whole supply chain.

Regarding increasing sales channels and sales volume, Bell et al. [11] used an econometric model to study preferred online retailers and to participate in key omnichannel decisions. The study suggests that increasing overall demand and online channels can attract customers with higher service costs, generate business spillover to other channels, and improve overall operational efficiency by increasing the conversion rate of sampling channels and reducing revenue. Lin [12] incorporated overlapping delivery and incomplete projects into the productiondistribution model, which contrasts with the traditional integration vendor-buyer coordination model. The study highlighted the observable fact that the system might experience shortages during the filtering period and it also considered quantity discounts, therefore increasing the sales volume. Lim et al. [13] studied the sales and operation planning problems of car manufacturers. Their study used numerical simulation to find the optimal balance between sales requirements and industry 
constraints, while limiting the inventory, emergency supply, and maintaining reasonable lead times for customers, therefore achieving the goal of increased sales. Lei and Moon [14] used principal component analysis (PCA) to propose a market-driven product positioning. They designed a decision support system (DSS), which enables companies to make more informed decisions about market-driven product positioning and design. This attracts more consumer attention and consumption, leading to increased product sales.

In potential mining customers, Baghalian et al. [15] developed a random mathematical formula for uncertain markets, to design more product supply chain networks, including several capable production facilities, distribution centres, and retailers. The study considered discrete sets of potential locations for distribution centres and retail stores and the impact of strategic location decisions on supply chain operational inventory and shipping planning. Gholamian et al. [16] examined the important issues of real-world supply chain production planning based on industry approvals. The supply chain model was studied using fuzzy multi-objective mixed integer nonlinear programming (FMOMINLP) and found that this mathematical model is mainly used to solve the problem of integrated multi-site, multi-cycle, and multi-product aggregation production planning (APP) under demand uncertainty. Jouzdani et al. [17] studied dynamic dairy facility locations and costs in supply chain planning. The proposed model dynamically combines possible changes to transportation networks, facility investment costs, the monetary value of time, and production processes. In addition, timing changes and demand uncertainty for dairy products during each planning period are considered to determine the optimal facility location and yield.

In terms of increasing sales through additional incentives, Zhong et al. [18] used data analysis to explore the benefits of proposed schemes using coupons for power systems in terms of social welfare, consumer surplus, load service entity (LSE) profits, retail price robustness, and implementation readiness, through coupon incentivebased demand response (CIDR) stimulation. Hua et al. [19] studied the best order volume and best retail price of retailers using the incentive of free delivery by suppliers. The study explicitly incorporated supplier volume discounts and shipping costs into the model, examining the impact of free shipping, volume discounts, and shipping costs on retailers' optimal volume and pricing decisions through analytical and digital means. Das and Dutta [20] developed a system dynamics framework for a closed-loop supply chain (CLSC) that relies on demand and reward incentives to establish a relationship between "the amount of reward offered to consumers" and "the probability of consumers returning used products to retailers." The performance analysis of the system dynamics simulation model shows that the inclusion of "incentive offers" can enhance the demand, collection, and remanufacturing process, resulting in more profits and better fill rates for the entire closedloop supply chain.
As for customer needs, Hamdouch et al. [21] proposed a decentralized closed-loop supply chain network model consisting of raw material suppliers, manufacturers, retailers, and recycling centres. The study assumes that the demand for the product and the corresponding return is stochastic and price-sensitive, and then deduces the optimal conditions for various decision-makers, establishing that the control equilibrium conditions can be expressed as finitedimensional variational inequalities. Numerical examples demonstrate the impact of demand and return uncertainty on quantity, shipments, and prices. Polotski et al. [22] proposed a novel numerical method based on time derivative estimation of numerical functions to cope with changes in demand and return. The study conducted extensive simulations to address several scenarios corresponding to the evolving relationship between manufacturing capacity and changing demand and return levels. The simulation results show that the optimal strategy has the important characteristics of predicting future changes in demand and return and in decision-making related to these changes in time. Heydari and Asl-Najafi [23] studied the synchronous coordination of order quantity and sales effort (SE) decisions in a random demand-related supplier/retailer system. The main objective of the proposed model was to achieve the optimal balance to provide a Pareto efficient solution for both channel members. The results show that the proposed revised sales rebate (RSR) contract leads to channel coordination, while both channel members experience Pareto improvements, and RSR contracts have great potential to eliminate the adverse effects of demand fluctuations on channel performance indicators.

Although all these articles consider the impact of customer demand on manufacturer profits, they consider the problem purely from the perspective of uncertain customer demand. However, in management practice, this paper finds that there is an interesting phenomenon of customer demand in the process of product marketing. For example, the original function of clothes is to keep warm, which also meets the need for human survival. However, with continuous social productivity, population income levels have greatly improved, so repeated purchasing of clothing no longer has an obvious negative impact on income levels and quality of life. Clothing now represents fashion and the pursuit of beauty, which is to say that people no longer buy clothes just to meet basic survival needs, but they now sublimate buying into the field of ideology. This interesting development holds for the vast majority of products. The factors influencing customer buying behaviour can be divided roughly into two types. First, there are the products that customers need to buy for daily life or within a certain period of time, i.e., necessities such as grain and oil. This type of demand represents real-world consumer needs and belongs to the "real demand" type of purchase. A customer in this situation is a customer with a real need. On the other hand, a customer may have no intention of buying a product, but due to the influence of external forces, they eventually buy the product. For example, a young man sees a brand of cosmetics advertised on TV and buys this product because the advertisement or social trend affected the 
consumer's purchasing behaviour. Consumers like this are categorized as customers with "false demand." The customers in between are known as customers with a "semireal" demand. These three different patterns of demand, real, false, and semi-real, $[24,25]$, cover a variety of products in various industries and become important factors influencing consumer purchasing behaviour.

Gathering research on the application of demand theory in the field of product supply chain for this study, it became clear that there was no literature available relating to systematic research on this particular and interesting aspect of demand. This study represents, therefore, groundbreaking research, the results of which will have a huge impact on demand theory in the field of marketing and supply chain strategy. This paper examines the product supply strategy of "real need" customers from a marketing point of view, that is to say, from the basis of the manufacturer's optimal product supply strategy in "real demand" patterns. Not only does this study fill an important research gap in product supply chain theory, but the results can also be applied to supply chain strategy in all industries where it has a very wide range of practical applications.

\section{Model Construction}

2.1. Real Demand Function. Petruzzi and Dada [26] studied the general demand function and believed that the randomness of demand has nothing to do with price. Mills [27] defined the demand function as the additive demand function model $D(p, \varepsilon)=y(p)+\varepsilon$. Karlin and Carr [28] defined the demand function as a multiplicative demand function model $D(p, \varepsilon)=y(p) \varepsilon$. Both $y(p)$ models are common in the economical pricing literature studied. In addition, the author extends the study of demand function to the value range of real demand, false demand, and semi-real demand [29-31]. Accordingly, we define the expression of the real demand function as [32]:

\section{Proposition 1. Definition of the real demand function.}

Definition 1. Definition of the real demand function is as follows:

$$
D_{T}=\frac{3}{2}\left(1-\frac{p-v p_{m}}{p_{m}(u-v)}\right)(a-b p+\varepsilon), \quad a, b>0, \varepsilon \in U\left(\mu, \sigma^{2}\right) .
$$

In this equation, $D_{T}$ is the real demand function, $p$ is the retail price of the product set by the manufacturer, $u$ is the functional performance of the product, $v$ is the utility function of the product, $P_{m}$ is the maximum product reserve price in the market, and $a$ and $b$ are commodity price coefficients [32].

2.2. Manufacturer's Profit Function. If the manufacturer wants to make a profit, he needs to produce the product and sell it. The difference between the two prices (production cost and sale price) is the profit the manufacturer can get. This involves two factors: (1) the marginal cost per unit of the product produced and the total number of products produced; and (2) whether the products produced can be sold, or how many units of the product can be sold and how much the price of each unit is of the product sold. To sum up, there are two situations when manufacturers sell their products: oversupply and undersupply.

If the marginal cost per unit of a product produced by the manufacturer is $c$ and the total quantity of product produced is $q$, the total cost of the product produced by the manufacturer is $c q$. Now, suppose the market demand for the product is $D(p, \varepsilon)$ and the selling price per unit of product is $p$. When the product is for sale, if the market situation for the state of demand is less than the supply, the product is not enough to sell; this means that the products produced by manufacturers are all can sell go out; at this point, the manufacturer is recovering funds for $p q$, profit for the $p q ; \prod_{m}(p, q)$ represents the manufacturer's profit function, associated with the retail price $p$ and the total production quantity $q$. If the market demand for the manufacturer's product is oversupply, the manufacturer cannot sell all the products produced and can only sell so many products based on market demand, $D(p, \varepsilon)$ at most. At the same time, the profit the manufacturer can get is $\prod_{m}(p, q)=-c q+p D(p, \varepsilon)$. Here, $\varepsilon$ represents the actual number of products sold as the market changes, which is a random variable. For the sake of simplicity, this paper assumes that the product sales volume obeys the density function of the uniform distribution on the interval $[-(a-b p),(a-b p)]$ :

$$
f(\varepsilon)=\frac{1}{2(a-b p)} .
$$

Proposition 2. Under the condition of real demand, the profit model of the manufacturer is as follows.

Therefore, based on the two situations above, the profit function of the developer can be expressed as

$$
\prod_{M}(p, q)=(p-c) q+\frac{3 p q^{2}\left(p_{m} u-p\right)}{8 p_{m}(u-v)(a-b p)}-\frac{p q^{2}}{2(a-b p)} \text {. }
$$

Proof. It proves that, according to the above analysis, the profit function of the manufacturer can be expressed as follows:

$$
\prod_{M}(p, q)= \begin{cases}-c q+p q, & D(p, \varepsilon) \geq q \\ -c q+p D(p, \varepsilon), & D(p, \varepsilon)<q\end{cases}
$$

In order to simplify the above model, probability and statistics theory can be used to obtain

$$
\begin{gathered}
\prod_{M}(p, q) \int_{q}^{2(a-b p)}[-c q+p q] \cdot f(\varepsilon) \mathrm{d} \varepsilon \\
+\int_{0}^{q}[-c q-p D(p, \varepsilon)] \cdot f(\varepsilon) \mathrm{d} \varepsilon .
\end{gathered}
$$

We use the density function of sales volume: 


$$
f(\varepsilon)=\frac{1}{2(a-b p)}
$$

$$
\begin{aligned}
& \prod_{M}(p, q)=(-c q+p q) \int_{q}^{2(a-b p)} \cdot \frac{1}{2(a-b p)} \mathrm{d} \varepsilon-c q \int_{0}^{q} \frac{1}{2(a-b p)} \mathrm{d} \varepsilon \\
& +p \int_{0}^{q} \frac{3}{2}\left(1-\frac{p-v p_{m}}{p_{m}(u-v)}\right) \varepsilon \cdot \frac{1}{2(a-b p)} \mathrm{d} \varepsilon \\
& =-c q \int_{0}^{q} \frac{1}{2(a-b p)} \mathrm{d} \varepsilon+p q \int_{q}^{2(a-b p)} \cdot \frac{1}{2(a-b p)} \mathrm{d} \varepsilon \\
& +\frac{3 p}{4} \cdot \frac{p_{m} u-p}{p_{m}(u-v)(a-b p)} \int_{0}^{q} \varepsilon \mathrm{d} \varepsilon \\
& =-c q+p q \cdot \frac{1}{2(a-b p)} \cdot[2(a-b p)-q]+\left.\frac{3 p\left(p_{m} u-p\right)}{4 p_{m}(u-v)(a-b p)} \cdot \frac{\varepsilon}{2}\right|_{0} ^{q} \\
& =(p-c) q-\frac{p q^{2}}{2(a-b p)}+\frac{3 p q^{2}\left(p_{m} u-p\right)}{8 p_{m}(u-v)(a-b p)}
\end{aligned}
$$

The proof of Proposition 2 is confirmed.

\section{Application and Analysis of the Mathematical Model}

Two mathematical models were constructed to represent the manufacturer's product supply strategy design for individual customers in the real demand pattern: (1) off-invoice mode and (2) unsold disposal mode, which solves the optimal yield, optimal pricing, and optimal rebate corresponding to the manufacturer's maximum profit.

\subsection{Off-Invoice Mode}

Proposition 3. The profit model and optimal value model under off-invoice mode.

In the definition of the real demand function (1) and the definition of the density function of sales volume (2), in the sales model of off-invoice, the manufacturer's profit function model is as follows:

$$
\prod_{M T}(p, q)=(-c+p-\alpha) q+\frac{3 q^{2}\left(p_{m} u-p\right)(p-\alpha)}{8 p_{m}(u-v)(a-b p)}-\frac{(p-\alpha) q^{2}}{2(a-b p)}
$$

$\alpha$ means the special price of each product.
Proof. In this supply mode, the products produced by the manufacturer are sold directly to customers. Assuming that the marginal cost of the manufacturer's products is $c$, and the total cost of the unit product of $q$ is $c q$, then the retail price of direct selling by the manufacturer to individual customers is $p$. Suppose that when the supply is sold directly to individual customers, each product is given $\alpha$, a discount, to promote sales. If the manufacturer produces more than it needs, it can only recoup its costs; if the manufacturer produces less than the quantity demanded, it can sell all the products and recoup $(p-\alpha) q$. Thus, the manufacturer's profit is

$$
\Pi_{M T}= \begin{cases}-c q+(p-\alpha) q, & D_{T}(p, \varepsilon) \geq q \\ -c q+(p-\alpha) D_{T}(p, \varepsilon), & D_{T}(p, \varepsilon)<q .\end{cases}
$$

We use definition (9) of mathematical expectation formula in probability statistics to obtain the following:

$$
\begin{aligned}
\prod_{M T}(p, q)= & \int_{q}^{2(a-b p)}[-c q+(p-\alpha) q] \cdot f(\varepsilon) \mathrm{d} \varepsilon \\
& +\int_{0}^{q}\left[-c q+(p-\alpha) D_{T}(p, \varepsilon)\right] f(\varepsilon) \mathrm{d} \varepsilon .
\end{aligned}
$$

We used the real demand function (1) and the density function of sales volume (2) to the above formula, integrated, and then obtained the following: 


$$
\begin{aligned}
& \prod_{M T}(p, q)=\left[\int_{q}^{2(a-b p)}-c q \cdot f(\varepsilon) \mathrm{d} \varepsilon+\int_{0}^{q}-c q \cdot f(\varepsilon) \mathrm{d} \varepsilon\right] \\
& +(p-\alpha) q \int_{q}^{2(a-b p)} f(\varepsilon) \mathrm{d} \varepsilon+(p-\alpha) \int_{0}^{q} D_{T}(p, \varepsilon) f(\varepsilon) \mathrm{d} \varepsilon \\
& -c q \int_{0}^{2(a-b p)} \frac{1}{2(a-b p)} \mathrm{d} \varepsilon+(p-\alpha) q \int_{q}^{2(a-b p)} \frac{1}{2(a-b p)} \mathrm{d} \varepsilon \\
& +(p-\alpha) \int_{0}^{q} \frac{3}{2}\left[1-\frac{p-v p_{m}}{p_{m}(u-v)}\right] \varepsilon \cdot \frac{1}{2(a-b p)} \mathrm{d} \varepsilon \\
& =-c q \cdot \frac{1}{2(a-b p)} \cdot 2(a-b p)+(p-\alpha) q \cdot \frac{1}{2(a-b p)}[2(a-b p)-q] \\
& +\left.\frac{3(p-\alpha)\left(p_{m} u-p\right)}{4 p_{m}(u-v)(a-b p)} \cdot \frac{\varepsilon^{2}}{2}\right|_{0} ^{q} \\
& =-c q+(p-\alpha) q-\frac{(p-\alpha) q^{2}}{2(a-b p)}+\frac{3(p-\alpha)\left(p_{m} u-p\right) q^{2}}{8 p_{m}(u-v)(a-b p)} \\
& =(-c+p-\alpha) q+\frac{3 q^{2}\left(p_{m} u-p\right)(p-\alpha)}{8 p_{m}(u-v)(a-b p)}-\frac{(p-\alpha) q^{2}}{2(a-b p)} .
\end{aligned}
$$

To obtain the optimal yield and optimal pricing so that the manufacturer can maximize profits in this supply mode, it is only necessary to apply the principle of optimization to take the derivative of the correlation function of equation (11) and set its derivative to 0 . The details are as follows.

Find the manufacturer's optimal production $q$; then,

$$
\left.\frac{\partial \prod_{M T}}{\partial q}=(-c+p-\alpha)\right)+\frac{3 q\left(p_{m} u-p\right)(p-\alpha)}{4 p_{m}(u-v)(a-b p)}-\frac{(p-\alpha) q}{a-b p}=0 \text {. }
$$

The value $q$ obtained from solution (12) is the manufacturer's optimal yield.

Moreover,

$$
\begin{aligned}
\frac{\partial \prod_{M T}}{\partial p}= & q+\frac{3 q^{2}\left(p_{m} u-2 p+\alpha\right)}{8 p_{m}(u-v)(a-b p)}+\frac{3 b q^{2}\left(p_{m} u-p\right)(p-\alpha)}{8 p_{m}(u-v)(a-b p)^{2}} \\
& -\frac{q^{2}}{2(a-b p)}-\frac{b(p-\alpha) q^{2}}{2(a-b p)^{2}}=0 .
\end{aligned}
$$

The value obtained from solution (13) is the manufacturer's optimal pricing.

Moreover,

$$
\frac{\partial \prod_{M T}}{\partial \alpha}=-q-\frac{3 q^{2}\left(p_{m} u-p\right)}{8 p_{m}(u-v)(a-b p)}+\frac{q^{2}}{2(a-b p)}=0 .
$$

The value of $\alpha$ obtained from solution (14) is the manufacturer's optimal rebate.

\subsection{Unsold Disposal Mode}

Proposition 4. The profit model and optimal value model under unsold disposal mode.

In the definition of the real demand function (1) and the definition of the density function of sales volume (2), under the unsold disposal mode, the manufacturer's profit function model is as follows:

$$
\prod_{M T}(p, q)=(-c+p) q+\frac{3 q^{2}\left(p_{m} u-p\right)(p-\gamma)}{8 p_{m}(u-v)(a-b p)}-\frac{(p-\gamma) q^{2}}{2(a-b p)} \text {. }
$$

$\gamma$ means the recovery price per unit of unsold product.

Proof. In this supply mode, discounts can be given to products that the manufacturer fails to sell. Suppose the manufacturer produces the product at the marginal cost of $c$, and the output is $q$; then, the manufacturer's total cost is $c q$. If the manufacturer's production is greater than the quantity demanded, it can only recover $p \cdot D_{T}(p, \varepsilon)$, and the remaining $q-D_{T}(p, \varepsilon)$ should be treated. For this part of the product, the manufacturer offers a discount treatment cost per unit of $\gamma$, so the total recovery price is $p D_{T}(p, \varepsilon)+\gamma\left(q-D_{T}(p, \varepsilon)\right)$. If the manufacturer produces 
less than the quantity demanded, it can sell all the products and recover $p q$. Thus, the manufacturer's profit is

$$
\prod_{M T}= \begin{cases}-c q+p q, & D_{T}(p, \varepsilon) \geq q, \\ -c q+p D_{T}(p, \varepsilon)+\gamma\left(q-D_{T}(p, \varepsilon)\right), & D_{T}(p, \varepsilon)<q .\end{cases}
$$

We use the definition (16) of mathematical expectation formula in probability statistics to obtain the following:

$$
\begin{aligned}
\prod_{M T}(p, q)= & \int_{q}^{2(a-b p)}(-c q+p q) \cdot f(\varepsilon) \mathrm{d} \varepsilon \\
& +\int_{0}^{q}\left[-c q+p D_{T}(p, \varepsilon)+\gamma\left(q-D_{T}(p, \varepsilon)\right)\right] \cdot f(\varepsilon) \mathrm{d} \varepsilon \\
= & {\left[-c q \int_{q}^{2(a-b p)} f(\varepsilon) \mathrm{d} \varepsilon-c q \int_{0}^{q} f(\varepsilon) \mathrm{d} \varepsilon\right]+p q \int_{q}^{2(a-b p)} f(\varepsilon) \mathrm{d} \varepsilon } \\
& +p \int_{0}^{q} D_{T}(p, \varepsilon) f(\varepsilon) \mathrm{d} \varepsilon \\
& +\gamma q \int_{0}^{q} f(\varepsilon) \mathrm{d} \varepsilon-\gamma \int_{0}^{q} D_{T}(p, \varepsilon) f(\varepsilon) \mathrm{d} \varepsilon \\
= & -c q \int_{0}^{2(a-b p)} f(\varepsilon) \mathrm{d} \varepsilon+p q \int_{q}^{2(a-b p)} f(\varepsilon) \mathrm{d} \varepsilon+\gamma q \int_{0}^{q} f(\varepsilon) \mathrm{d} \varepsilon \\
& +(p-\gamma) \int_{0}^{q} D_{T}(p, \varepsilon) f(\varepsilon) \mathrm{d} \varepsilon .
\end{aligned}
$$

We used the real demand function (1) and the density function of sales volume (2) in the above equation, then integrated, and obtained the following.

$$
\begin{aligned}
\prod_{M T}(p, q)= & -c q \int_{0}^{2(a-b p)} \frac{1}{2(a-b p)} \mathrm{d} \varepsilon+p q \int_{q}^{2(a-b p)} \frac{1}{2(a-b p)} \mathrm{d} \varepsilon \\
& +\gamma q \int_{0}^{q} \frac{1}{2(a-b p)} \mathrm{d} \varepsilon+(p-\gamma) \int_{0}^{q} \frac{3}{2}\left[1-\frac{p-v p_{m}}{p_{m}(p-v)}\right] \varepsilon \cdot \frac{1}{2(a-b p)} \mathrm{d} \varepsilon \\
= & -\left.c q \cdot \frac{\varepsilon}{2(a-b p)}\right|_{0} ^{2(a-b p)}+\left.p q \cdot \frac{\varepsilon}{2(a-b p)}\right|_{q} ^{2(a-b p)} \\
& +\left.\frac{\gamma q}{2(a-b p)} \cdot \varepsilon\right|_{0} ^{q}+\left.\frac{3(p-\gamma)\left(p_{m} u-p\right)}{4 p_{m}(u-v)(a-b p)} \cdot \frac{\varepsilon^{2}}{2}\right|_{0} \\
& -c q+p q-\frac{p q^{2}}{2(a-b p)}+\frac{\gamma q^{2}}{2(a-b p)}+\frac{3(p-\gamma)\left(p_{m} u-p\right) q^{2}}{8 p_{m}(u-v)(a-b p)} \\
= & (-c+p) q+\frac{3 q^{2}(p-\gamma)\left(p_{m} u-p\right) q^{2}}{8 p_{m}(u-v)(a-b p)}-\frac{(p-\gamma) q^{2}}{2(a-b p)} .
\end{aligned}
$$

To obtain the optimal yield and optimal pricing so that the manufacturer can maximize profits in this supply mode, it is only necessary to apply the principle of optimization to take the derivative of the correlation function of equation (18) and set its derivative to 0 . The details are as follows. To obtain the optimum yield of the manufacturer, then, 


$$
\frac{\partial \prod_{M T}}{\partial q}=(-c+p)+\frac{3 q(p-\gamma)\left(p_{m} u-p\right)}{4 p_{m}(u-v)(a-b p)}-\frac{q(p-\gamma)}{a-b p}=0 .
$$

The $q$ value obtained from solution (19) is the optimal output of the manufacturer.

And then,

$$
\begin{aligned}
\frac{\partial \prod_{M T}}{\partial p}= & q+\frac{3 q^{2}\left(p_{m} u-2 p+\gamma\right)}{8 p_{m}(u-v)(a-b p)}+\frac{3 b q^{2}(p-\gamma)\left(p_{m} u-p\right)}{8 p_{m}(u-v)(a-b p)^{2}} \\
& -\frac{q^{2}}{2(a-b p)}-\frac{b q^{2}(p-\gamma)}{2(a-b p)^{2}}=0 .
\end{aligned}
$$

The value obtained from solution (20) is the manufacturer's optimal pricing.

\section{Analysis of Examples}

Since manufacturers design and plan supply strategies for individual customers in the real demand pattern, the relationship of variables in the mathematical model to achieve the optimal profit is very complicated, and there is no explicit solution for optimal yield (sales volume) $q^{*}$ and optimal price $p^{*}$. Therefore, in order to verify whether the model really reflects the product supply strategy under different demand patterns and whether the model correctly reflects the relationship between variables, this paper will verify the optimal solution of the model through numerical examples. Suppose a manufacturer plans to produce and sell a common product, and the single production cost of this product is set at 50. If the production volume is large enough to further reduce the cost, and the current maximum retail price of this product on the market is set at 100 , the manufacturer then needs to meet the retail price of the product directly sold to individual customers to realize profitability. So, the question we intend to solve is how do manufacturers determine optimal yield and optimal prices?

This paper considers the effect of production volume on prices and returns. Before solving the model, the related variables are defined. In the equation, $0 \sim 2(a-b p)$ is the range of the manufacturer's production, $p$ is the retail price that the manufacturer is selling directly to individual customers, $q$ is the manufacturer's production volume, $\alpha$ is the manufacturer's re-discount to individual customers, $c$ is the manufacturer's marginal cost, $p_{m}$ is the highest price sold by the retailer, $\gamma$ is the manufacturer's discount processing cost, $u$ is the product's utility efficiency, and $v$ is the product grade function efficiency. Set the basic parameters as follows: $a=90, c=50, b=0.5, p_{m}=100, u=1.2, v=0.5$.

4.1. Off-Invoice Mode. Suppose the manufacturer's marginal cost of producing a product is $c$, the total cost of producing $q$ units is $c q$, and the retail price of the manufacturer's direct sales to individual customers is $p$. If the manufacturer produces more than the quantity demanded, it can only recover the cost $(p-\alpha) D_{T}(p, \varepsilon)$. If the manufacturer produces less than the quantity demanded, all the products can be sold and recover $(p-\alpha) q$. At the same time, to examine the influence mechanism of the manufacturer's re-discount $\alpha$ to individual customers on optimal yield and optimal price, numerical calculations will be performed with an increment of 1.0 within the interval $(1.0,6.0)$ in this paper.

Using Mathematica 8.0, the basic parameters set are substituted into equations (12) and (13) to solve the problem, and the optimal yield and price of the manufacturer can be obtained.

Numerical calculation shows that, under the direct discount sales mode, there is only one optimal solution satisfying the constraint conditions. Therefore, this optimal solution is calculated (see Table 1 for the calculated results). It can be seen from Table 1 that, in this distribution mode, the optimal price and optimal yield are both greater than 0 , thus verifying the effectiveness of the model. In addition, this paper finds that the higher the preferential value $a$, the better the pricing $p$ is proportional to the best production $q$. According to the law of commodity operation, if the increase in demand is less than the increase in price, it will increase the total revenue. As a result, as the value of $a$ gets larger, the pricing goes down. When production increases, the total revenue for the manufacturer will be larger, as will the expected profit.

This article extends the data in Table 1 to Figure 1 through the mapping capabilities of Mathematica 8.0. As shown in Figure 1, the horizontal axis represents price $p$ and the vertical axis represents production $q$. In direct discount mode, the relationship between optimal pricing and optimal yield presents an inverted parabolic relationship. At this point (see Figure 1), the highest point of the upward trend of the parabola is the manufacturer's optimal pricing. However, due to the actual commodity trading process, a variety of unstable factors such as bargaining may be present. Therefore, according to the three-sigma principle theorem by Pukelsheim [33], this paper shows that the manufacturer's profit can be maximized in the realistic state when the product is priced in the range $(78,82)$. At this point on the scale, according to the theory of optimization, the manufacturer's profit reached the optimal return.

However, if the fixed value of the product is below 56 and the $q$ value of the output is negative, this is not in line with the economic law of commodities, so it can be deduced that the manufacturer's production is at a loss.

4.2. Unsold Disposal Mode. In this supply model, discounts are given to products that the manufacturer fails to sell. Suppose the manufacturer produces the product at the marginal cost of $c$, and the output is $q$; then, the manufacturer's total cost is $c q$. If the manufacturer's production is greater than the demand, it can only recover $p \cdot D_{T}(p, \varepsilon)$, and the remaining $q-D_{T}(p, \varepsilon)$ should also be processed. For this part of the products, the manufacturer gives discount treatment cost per unit $\gamma$, and the total recovery price is $p D_{T}(p, \varepsilon)+\gamma\left(q-D_{T}(p, \varepsilon)\right)$. If the manufacturer's production is less than the quantity demanded, all products can be sold and $p q$ can be recovered. At the same time, to examine the influencing mechanism of manufacturer's 
TABLE 1: Optimal yield and optimal price in off-invoice mode.

\begin{tabular}{lcc}
\hline$\alpha$ & $p$ & $q$ \\
\hline 1.0 & 51.01 & 0.04 \\
2.0 & 52.01 & 0.04 \\
3.0 & 53.01 & 0.04 \\
4.0 & 54.01 & 0.03 \\
5.0 & 55.01 & 0.03 \\
6.0 & 56.01 & 0.03 \\
\hline
\end{tabular}

Source: numerical results.

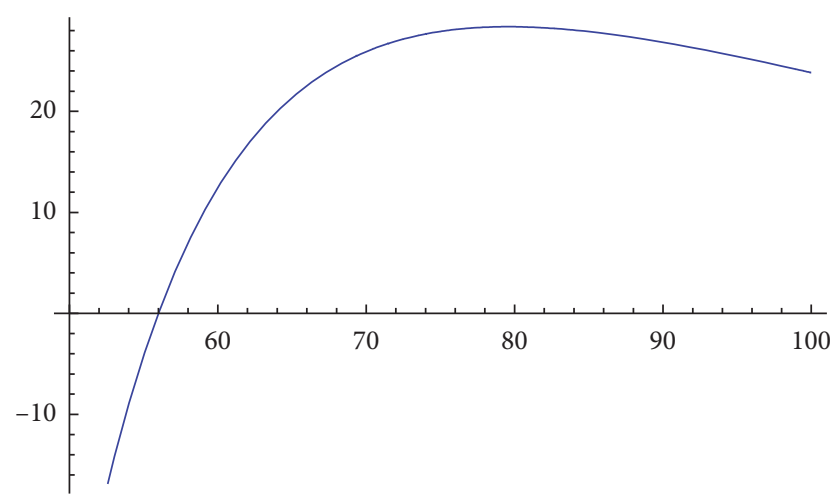

FiguRE 1: Variation trend of manufacturer's optimal pricing with optimal order quantity in the off-invoice mode.

discount treatment fee $\gamma$ on optimal yield and optimal price, a numerical calculation will be conducted with an increase of 1 within the range of $(40,45)$.

Using Mathematica 8.0, the basic parameters set are substituted into equations (19) and (20) to solve the problem, and the optimal yield and optimal price of the manufacturer can be obtained.

Numerical calculations show that there is only one optimal solution satisfying the constraint condition $50<p \leq 100$ in the unsold disposal selling mode. The optimal solution is calculated (see Table 2 for the calculated results). Table 2 shows that, under this distribution model, the optimal price and optimal yield are both greater than 0 , and the validity of the model is verified. In addition, this paper finds that the higher the $\gamma$ value of discount processing cost, the higher the proportion between the optimal pricing and optimal yield volume. According to the law of commodity operation, if the increase in demand is greater than the decline in price, the total revenue will increase. Therefore, as the $\gamma$ value gets larger, pricing presents a downward trend, and the production volume increases, and the manufacturer's total revenue increases, along with the expected profit.

To analyze the changes of the preferential value, best yield, and the best pricing more intuitively, this paper extends Table 2 to Figure 2 through the mapping function of Mathematica 8.0. As shown in Figure 2, the horizontal axis represents the price $p$ and the vertical axis represents production $q$. In the unsold disposal mode, the relationship between optimal pricing and optimal yield presents an inverted parabolic relationship. At this point (see Figure 2), the highest point of the upward trend of the parabola represents the manufacturer's optimal pricing. According to
TABLE 2: Optimal yield and optimal price in unsold disposal mode.

\begin{tabular}{lcc}
\hline$\gamma$ & $p$ & $q$ \\
\hline 40 & 94.77 & 47.74 \\
41 & 94.18 & 49.28 \\
42 & 93.56 & 50.94 \\
43 & 92.90 & 52.76 \\
44 & 92.20 & 54.75 \\
45 & 91.44 & 56.94 \\
\hline
\end{tabular}

Source: numerical results.

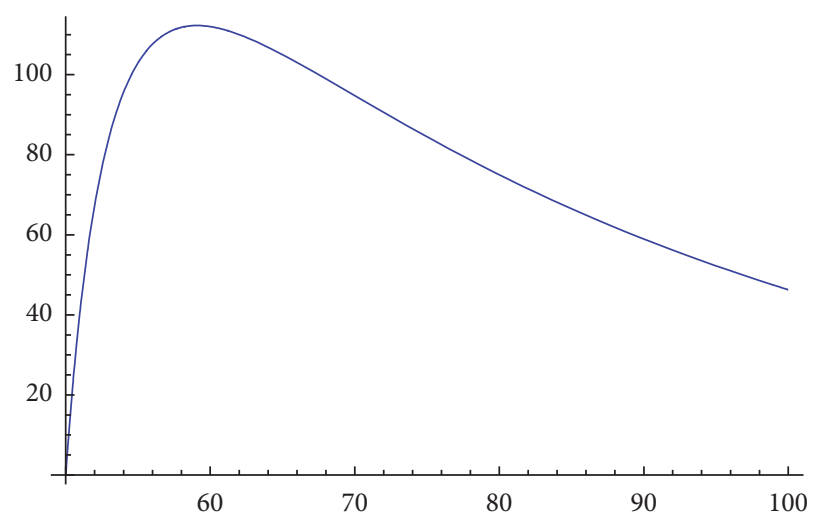

FIgURE 2: Variation trend of manufacturer's optimal pricing with optimal order quantity in unsold disposal mode.

the three-sigma principle theorem by Pukelsheim [33], the products sold by the manufacturer to individual customers are priced in the range $(58,60)$, and the manufacturer's profit can be maximized in the realistic state. According to the theory of optimization, the manufacturer's profit is optimal.

\section{Promotion of the Model}

By establishing the model, we studied the precision marketing strategy of manufacturers in the real demand mode. According to the model, we obtained the optimal yield and optimal price of the product for the manufacturer. The calculation results in Tables 1 and 2 further verified the correctness of the propositions in the research. Although we only consider the parameter values within a specific range in the numerical examples, the verification results are all greater than 0 ; we will further analyze the model by changing the value of the parameters. According to the definition of the real demand function, we will only analyze the impact of the change of the utility efficiency $u$ of the product on the optimal yield and optimal pricing of the manufacturer, so $u-v>0,0<u<1$. Since we are only discussing the universality of the model, the results in Tables 1 and 2 show that the value of $\alpha$ and $\gamma$ will not have an essential impact on the final result. Due to space limitation, when the value range of other parameters remains unchanged, we only set $\alpha$ as 1.0, set $\gamma$ as 44 , and then verify the models for $u$ as $0.6,0.7,0.8$, and 0.9 , respectively. We substitute different values of the product's utility efficiency $u$ into equations of (12), (13), (19), and (20), respectively, to get the results, and the results are 
TABLE 3: The influence of the change of product utility efficiency $u$ on optimal yield and optimal pricing.

\begin{tabular}{cccccc}
\hline$u$ & \multicolumn{2}{c}{$\alpha$} & & \multicolumn{2}{c}{$\gamma$} \\
& $p_{1}$ & & $q_{1}$ & $p_{2}$ & $q_{2}$ \\
\hline 0.6 & 51.01 & 0.03 & 80.00 & 16.67 \\
0.7 & 51.01 & 0.03 & 83.53 & 27.14 \\
0.8 & 51.01 & & 0.03 & 86.22 & 34.81 \\
0.9 & 51.01 & 0.03 & 88.39 & 40.84 \\
\hline
\end{tabular}

shown in Table 3 . When the product's utility efficiency $u$ changes, it is verified that the proposition is still valid. Thus, the universality of the model is explained; that is, the model can effectively solve the manufacturer's precision marketing strategy under the real demand model.

\section{Conclusion}

Product supply strategy under various demand patterns has a huge influence on supply chain management. The solution to this problem is to achieve the optimal profit of products by finding the optimal pricing and sales volume set by manufacturers or retailers for individual customers and group customers under varying demand patterns.

What makes this paper special is that, firstly, we have considered the demand function based on different demand patterns and the manufacturer's profit function. Secondly, the mathematical models of off-invoice mode and unsold disposal mode in the product supply strategy for the "real demand" pattern are constructed by using the relevant principles of probability theory, partial differential equation, and optimization theory. Thirdly, the optimal pricing and optimal yield were obtained, and the numerical results verified the effectiveness and feasibility of the model. Moreover, it can also help manufacturers or retailers to make more accurate product sales decisions for individual customers and group customers under different demand patterns.

In the future, further consideration of the optimal product pricing strategies of manufacturers and retailers for individual customers and group customers is proposed, using the "false demand" and "semi-real demand" patterns. These pricing strategies could also be tested through empirical data, to make further comparative analysis.

\section{Data Availability}

No data were used to support this study.

\section{Conflicts of Interest}

The authors declare that they have no conflicts of interest.

\section{Acknowledgments}

This work was supported by the National Natural Science Foundation of China (no. 11571159) and the Foundation of Wuyi University (YJ202012).

\section{References}

[1] M. L. Dai, Demand Economics, China Development Press, Beijing, China, 2015.

[2] Q. Wang, J. Li, H. Yan, and S. X. Zhu, "Optimal remanufacturing strategies in name-your-own-price auctions with limited capacity," International Journal of Production Economics, vol. 181, pp. 113-129, 2016.

[3] C. Li and A. Lim, "A greedy aggregation-decomposition method for intermittent demand forecasting in fashion retailing," European Journal of Operational Research, vol. 269, no. 3, pp. 860-869, 2018.

[4] U. Chanda and A. Kumar, "Optimisation of fuzzy EOQ model for advertising and price sensitive demand model under dynamic ceiling on potential adoption," International Journal of Systems Science: Operations \& Logistics, vol. 4, no. 2, pp. 145-165, 2017.

[5] M. Palanivel and R. Uthayakumar, "A production-inventory model with promotional effort, variable production cost and probabilistic deterioration," International Journal of System Assurance Engineering and Management, vol. 8, no. S1, pp. 290-300, 2017.

[6] P. Zhang, Y. He, and C. Shi, "Retailer's channel structure choice: online channel, offline channel, or dual channels?" International Journal of Production Economics, vol. 191, pp. 37-50, 2017.

[7] P. Zhang, Y. He, and X. Zhao, “"Preorder-online, pickup-instore" strategy for a dual-channel retailer," Transportation Research Part E: Logistics and Transportation Review, vol. 122, pp. 27-47, 2019.

[8] P. He, Y. He, and H. Xu, "Channel structure and pricing in a dual-channel closed-loop supply chain with government subsidy," International Journal of Production Economics, vol. 213, pp. 108-123, 2019.

[9] Y. He and X. Zhao, "Coordination in multi-echelon supply chain under supply and demand uncertainty," International Journal of Production Economics, vol. 139, no. 1, pp. 106-115, 2016.

[10] Y. He and X. Zhao, "Contracts and coordination: supply chains with uncertain demand and supply," Naval Research Logistics, vol. 63, no. 4, pp. 305-319, 2016.

[11] D. R. Bell, S. Gallino, and A. Moreno, "Offline showrooms in omnichannel retail: demand and operational benefits," Management Science, vol. 64, no. 4, pp. 1629-1651, 2018.

[12] T.-Y. Lin, "Coordination policy for a two-stage supply chain considering quantity discounts and overlapped delivery with imperfect quality," Computers \& Industrial Engineering, vol. 66, no. 1, pp. 53-62, 2013.

[13] L. L. Lim, G. Alpan, and B. Penz, "Reconciling sales and operations management with distant suppliers in the automotive industry: a simulation approach," International Journal of Production Economics, vol. 151, pp. 20-36, 2014.

[14] N. Lei and S. K. Moon, "A decision support system for market-driven product positioning and design," Decision Support Systems, vol. 69, pp. 82-91, 2015.

[15] A. Baghalian, S. Rezapour, and R. Z. Farahani, "Robust supply chain network design with service level against disruptions and demand uncertainties: a real-life case," European Journal of Operational Research, vol. 227, no. 1, pp. 199-215, 2013.

[16] N. Gholamian, I. Mahdavi, and R. Tavakkoli-Moghaddam, "Multi-objective multi-product multi-site aggregate production planning in a supply chain under uncertainty: fuzzy multi-objective optimization," International Journal of Computer Integrated Manufacturing, vol. 29, pp. 149-165, 2016. 
[17] J. Jouzdani, S. J. Sadjadi, and M. Fathian, "Dynamic dairy facility location and supply chain planning under traffic congestion and demand uncertainty: a case study of Tehran," Applied Mathematical Modelling, vol. 37, no. 18-19, pp. 8467-8483, 2013.

[18] H. Zhong, L. Xie, and Q. Xia, "Coupon incentive-based demand response: theory and case study," IEEE Transactions on Power Systems, vol. 28, no. 2, pp. 1266-1276, 2013.

[19] G. Hua, S. Wang, and T. C. E. Cheng, "Optimal order lot sizing and pricing with free shipping," European Journal of Operational Research, vol. 218, no. 2, pp. 435-441, 2012.

[20] D. Das and P. Dutta, "Performance analysis of a closed-loop supply chain with incentive-dependent demand and return," The International Journal of Advanced Manufacturing Technology, vol. 86, no. 1-4, pp. 621-639, 2016.

[21] Y. Hamdouch, Q. P. Qiang, and K. Ghoudi, "A closed-loop supply chain equilibrium model with random and pricesensitive demand and return," Networks and Spatial Economics, vol. 17, no. 2, pp. 459-503, 2017.

[22] V. Polotski, J.-P. Kenné, and A. Gharbi, "Production control of hybrid manufacturing-remanufacturing systems under demand and return variations," International Journal of Production Research, vol. 57, no. 1, pp. 100-123, 2019.

[23] J. Heydari and J. Asl-Najafi, "A revised sales rebate contract with effort-dependent demand: a channel coordination approach," International Transactions in Operational Research, vol. 28, no. 1, pp. 438-461, 2018.

[24] M. Crawford, "The world in a shopping mall," in Variations on a Theme Park: The New American City and the End of Public Space, M. Sorkin, Ed., pp. 3-30, Hill and Wang, New York, NY, USA, 2004.

[25] H. Marcuse, One-Dimensional Man: Studies in the Ideology of Advanced Industrial Society, Beacon Press, Boston, MA, USA, 2nd edition, 1991.

[26] N. C. Petruzzi and M. Dada, "Pricing and the newsvendor problem: a review with extensions," Operations Research, vol. 47, no. 2, pp. 183-194, 1999.

[27] E. S. Mills, "Uncertainty and price theory," The Quarterly Journal of Economics, vol. 73, no. 1, pp. 116-130, 1959.

[28] S. Karlin and C. R. Carr, "Prices and optimal inventory policy," in Applied Probability and Management Science, K. J. Arrow, S. Karlin, and H. Scarf, Eds., pp. 159-172, Stanford University Press, Stanford, CA, USA, 1962.

[29] Z. Y. Zhuo, "Research on optimal product supply strategies for manufacturer-to-group customer under a real demand pattern," International Journal of Operational Research, In press, 2020.

[30] Z. Zhuo, "New mathematical model of retailer-to-individual customer optimal product supply strategies under false demand pattern: customer discount mode," Journal of Mathematics Research, vol. 12, no. 1, pp. 36-42, 2020.

[31] Z. Zhuo, K. Y. Chau, S. Z. Huang, and Y. K. Ip, "Mathematical modelling of optimal product supply strategies for manufacturer-to-group customers based on semi-real demand patterns," International Journal of Operational Research, vol. 1 , no. 1, pp. 1-8, 2020.

[32] Z. Y. Zhuo, S. H. Chen, H. Yan, and Y. He, "Models for retailers' supply strategies aimed at individual customers under the real demand pattern," Chiang Mai Journal of Science, In press, 2020.

[33] F. Pukelsheim, "The three sigma rule," The American Statistician, vol. 48, no. 2, pp. 88-91, 1994. 